Available online at GSC Online Press Directory

GSC Biological and Pharmaceutical Sciences

e-ISSN: 2581-3250, CODEN (USA): GBPSC2

Journal homepage: https://www.gsconlinepress.com/journals/gscbps

(RESEARCH ARTICLE)

\title{
Physiological and biochemical implications of prenatal exposure to acetaminophen and Piliostigma thonningii extract on the renal function indices of female rats
}

\author{
Nkanu EE ${ }^{1}$, Dasofunjo $\mathrm{K}^{2 *}$, Ujong UP ${ }^{2}$ and Amaku EE ${ }^{1}$ \\ ${ }^{1}$ Department of Human Physiology, Cross River University of Technology, Okuku Campus, Nigeria. \\ ${ }^{2}$ Department of Medical Biochemistry, Cross River University of Technology, Okuku Campus, Nigeria.
}

Publication history: Received on 09 June 2020; revised on 30 June 2020; accepted on 03 July 2020

Article DOI: https://doi.org/10.30574/gscbps.2020.12.1.0170

\begin{abstract}
N-Acetyl-p-Aminophenol (APAP), also known as acetaminophen, is the most commonly used over-the counter analgesic and antipyretic medication. However, its overdose leads to both liver and kidney damage. This research work assessed the effect of prenatal exposure to Piliostigma thonningii on some renal function indices following acetaminophen induced toxicity. The leaves of $P$. thonningii were collected and air dried for 14 days until constant weight was obtained. Twenty-five (25) pregnant female rats $(180$ - 200) g was grouped on the bases of their weight to five (5) groups of 5 rats each. Animals in group A served as control while groups B-E served as the treated groups. Group B was administered with $200 \mathrm{mg} / \mathrm{kgb} . w t$ of acetaminophen, Group C was administered $200 \mathrm{mg} / \mathrm{kgb}$. wt of $P$. thonningii, Group D was administered with $100 \mathrm{mg} / \mathrm{kgb}$. wt of $P$. thonningii $+200 \mathrm{mg} / \mathrm{kgb}$. wt of acetaminophen, while group E was administered $200 \mathrm{mg} / \mathrm{kgb}$. wt of $P$. thonningii $+200 \mathrm{mg} / \mathrm{kgb}$. wt of acetaminophen. The administration was done for 28days/till parturition. The dams were fed for 21day and five from each group were sacrificed and blood collected by cardiac puncture in sterile plane tubes for prenatal renal function assessment. The result shows $(\mathrm{p}<0.05)$ significant increase in $\mathrm{Na}^{+}$concentration of groups administered with acetaminophen alone, with evidence of significant decrease in groups administered with P.thonningii alone. The result also show that prenatal exposure to P.thonningii produced no significant difference on serum $\mathrm{K}^{+}, \mathrm{Cl}^{-}, \mathrm{HCO}_{3}$, urea,creatinine, ALT,AST and ALP. It was speculated that prenatal exposure to acetaminophen produced no assault on the functional integrity of the kidney but with an evidence of hypernatremia which may be due to increase in aldosterone level.
\end{abstract}

Keywords: Acetaminophen; Analgesic; Hypernatremia; Functional integrity of the kidney

\section{Introduction}

Acetaminophen (APAP) is one of the most commonly used analgesic and antipyretic drugs. There is probable potentiation of hepatotoxicity following an overdose from the paracetamol metabolite, $\mathrm{N}$-acetyl-para-benzoquinonimine (NAPQI) by enzyme-inducing drugs. Several studies have shown that the pharmacokinetic behaviour, optimal dosage, renal clearance and urinary excretion of various drugs are different under indigenous conditions [1]. Prostaglandin inhibitors such as NSAIDs, and potentially APAP in toxic doses, may have various effects on the kidney. Renal injury may partly be due to vasoconstriction as a consequence of inhibition of kidney prostaglandin-mediated vasodilation, resulting in renal hypo perfusion and consequent reduction in the glomerular filtration rate [2]. NSAIDinduced renal injury is affected by the dose of drug, the duration of the pharmacologic effect, and the health status of the patient. Individuals who are poorly hydrated and have compromised renal function are more likely to develop acute renal injury [2]. APAP in a toxic dose induced renal failure. The incidence of APAP-induced renal failure has been reported to be approximately $2 \%$, and it reaches $10 \%$ in severe cases. Although most cases of renal failure are associated with hepatic injury, renal damage in the absence of hepatic injury has been reported. It is still unknown whether this effect is due to a direct APAP nephrotoxic effect or as a consequence of hepatic failure. A single nonlethal dose of APAP

\footnotetext{
* Corresponding author: Dasofunjo K; dasokay22@gmail.com; kayodedasofunjo@crutech.edu.ng
} 
on animals with high levels of renal microsomal P-450 activity caused proximal convoluted tubular necrosis, possibly as a result of local production of the toxic intermediate metabolite known as para-benzoquinoneimine [3]. Hemodynamic changes in the kidney through COX inhibition, similar to the action of classical NSAIDs, are another suggested mechanism for APAP-induced nephrotoxicity.

Traditional medicine has remained the most affordable and easily accessible source for management of disease and they provide an important source of the world's pharmaceuticals. Piliostigma thoningii plant is known across tropical Africa continent and other sub-sahara countries as camel's foot (English); In Nigeria it bears such local names as okpoatu (Igbo), ejei-jei (Igala), Kalog (Hausa), omepa (Igede), nyihar( Tiv) ,Yala (obepa) [4].

However, there are many reported folkloric claims on the medicinal usefulness of this plant which ranges from heamatopoietic, antilipidaemic, hepatoprotective, aphrodisiac, antimalaria, anti-venom [5,6]. Therefore, this research is aimed at determining the effect of prenatal exposure to acetaminophen and Piliostigma thonningii on the renal function indices of rats.

\section{Material and methods}

\subsection{Plant material}

Fresh P.thonningii leaves were obtained from Igoli/Okuku road, Cross River State, Nigeria in February, 2017.Identification and authentication was done at the Federal College of Forestry Jos, Plateau State, Nigeria, with the voucher number \#25.

\subsection{Assay kit}

Fortress diagnostics for sodium urea creatinine chlorides and teco diagnostic kit for potassium were used to determine renal function test.

\subsection{Experimental animals}

Twenty five (25) virgin female Wistar rats were obtained from animal holding unit, Department of Medical Biochemistry Okuku. The animals was acclimatized for a period of seven (7) days. Each rat was housed in a woodened cage. The animal room was well ventilated and kept at room temperature and relative humidity of $27{ }^{\circ} \mathrm{C}$ and $70 \%$ respectively with 12 hours natural light - dark cycle and were allowed free access to standard feed and water. Good hygiene was maintained by constant cleaning and removal of feaces and spilled feeds from cages daily. The animals were subcutaneously injected with $0.1 \mathrm{mg} / \mathrm{kg}$ body weight of diethylstilbestrol in $0.5 \mathrm{ml}$ olive oil to ensure the female rats were in oestrous. The mature male rats were introduced in ratio 1:3 until they have been confirmed pregnant.

\subsection{Preparation of ethanol extract of Piliostigma thonningii leaf}

The leaves of $P$. thonningii were collected and air dried for 14 days until constant weight was obtained. The dried leaves were then pulverized after which $300 \mathrm{~g}$ was extracted in $1000 \mathrm{ml}$ of ethanol for 72 hours with constant shaking using the electric shaker. This was later filtered using Whatman No.1 filter paper. The filtrates were the concentrated in water bath at $45^{\circ} \mathrm{C}$. The resulting slurry was weighed and reconstituted in coil oil to administer the required dose.

\subsection{Animal grouping and administration of extract}

Twenty five (25) pregnant female albino rats were picked at random and placed into wooden cages labeled A-D. Group A served as control while groups B -D were test groups. The animals in group A were administered orally with distilled water. Group B were administered $200 \mathrm{mg} / \mathrm{kg}$ body weight of acetaminophen, Group C was administered $200 \mathrm{mg} /$ body weight of the extract while group D was administered with $200 \mathrm{mg} / \mathrm{kg}$ body weight of acetaminophen and P. thonningii respectively. All experimental groups used corn oil as vehicle. The oral administration was done for 28 days (till parturition)i.e till the dams gave birth. The offspring were carefully separated and cared for until they were weaned on day 21 .The animals in each group were sacrificed 24 hours by cardiac puncture procedure. The animals were handled humanely in accordance with the guidelines of European convention for the protection of vertebrate animals and other scientific purposes. Ethical approval for the study was obtained from the Faculty of Basic Medical Science Animal Research Ethical Committee of Cross River University of Technology, Calabar, Nigeria (approval number FBMS/CRUTECH/12/021). 


\subsection{Blood sample collection}

Blood was collected from all the test rats and control by cardiac puncture under plane sterile tubes for serum electrolytes, preceded by centrifuging and separation of the blood plasma with a standard pipette.

\subsection{Preparation of kidney homogenate}

The kidneys of the rats were removed under the same condition and the surrounding fatty tissues were removed from the organs, as they could make the homogenization process more difficult.

The process was carried out by blending each organ of each rat separately in $2 \mathrm{mls}$ of $1 \%$ glucose solution until a relatively smooth homogenate was formed. The homogenate of each organ was centrifuge for $15 \mathrm{mins}$ followed by extraction of the liquid homogenate into sterile plane test tube.

\subsection{Statistical analysis}

Data collected was statically analyzed using graph pad way 5.0 (USA) and presented in tables and figures.

\section{Results}

The result below shows the prenatal electrolyte profile. It was observed that the sodium concentration of acetaminophen only group and Acetaminophen and extract of Piliostigma thonningii (A.P T )low dose were significantly greater than control both at $(\mathrm{p}<0.001)$. Also extract of Piliostigma thonningii $(\mathrm{P} . \mathrm{T})$ only group had lower sodium concentration compared to acetaminophen only group and Acetaminophen and extract of Piliostigma thonningii $(\mathrm{A}+\mathrm{P})$ low dose both at $(\mathrm{P}<0.05)$ (fig .1).

Prenatal $\mathrm{K}+$ concentration was not significantly different in the other treatment groups compared to control. However, P.T only group had significantly lower $\mathrm{K}+$ concentration compared to A+P.T low dose at $(\mathrm{P}<0.05)$ (fig. 2). Prenatal $\mathrm{Cl}$ concentration of control rats was significantly lowered than all the other treatment groups at $(\mathrm{P}<0.001)$. A $+\mathrm{P}$ low dose and $\mathrm{A}+\mathrm{P}$ high dose groups were both significantly lower than acetaminophen only group at $\mathrm{P}<0.05$ and $\mathrm{P}$.T only at $\mathrm{P}<0.05$ respectively (fig 3 ).

The prenatal $\mathrm{HCO} 3$ and urea concentration in all the treatment groups were not significantly different $(\mathrm{P}<0.05)$ from control and from one another (fig 4-5). Prenatal uric acid concentration was not significantly different $(\mathrm{P}<0.05)$ in the other treatment groups compared to control. However, P.T only group had significantly lower uric acid concentration compared to $\mathrm{A}+\mathrm{P}$. $\mathrm{T}$ low dose at $(\mathrm{P}<0.05)$ (fig 6). It was observed that following the administration of the drugs , the prenatal creatinine concentration of acetaminophen only group was significantly different from control, P.T only, A+P.T low dose and A+ P.T high dose groups all at $\mathrm{P}<0.001$ (fig 7). Following the prenatal exposure to the drug, the prenatal serum enzyme concentration indicated no significant $d$ in the concentration of ALT, AST and ALP between the treatment group and control and from one another at $(\mathrm{P}<0.05)$ (fig 8-10).

For all figures in the manuscript

Values are presented as mean \pm standard deviation; $n=5$

a- represent significantly different from control

b- represent significantly different from acetaminophen only

c- represent significantly different from P.thonningii only

d- represent significantly different from acetaminophen and P.thonningii low dose

One superscript represent significant difference at $p<0.05$

Two similar superscript represent significant difference at $\mathrm{p}<0.01$

Three similar superscript represent significant difference $\mathrm{p}<0.001$ 


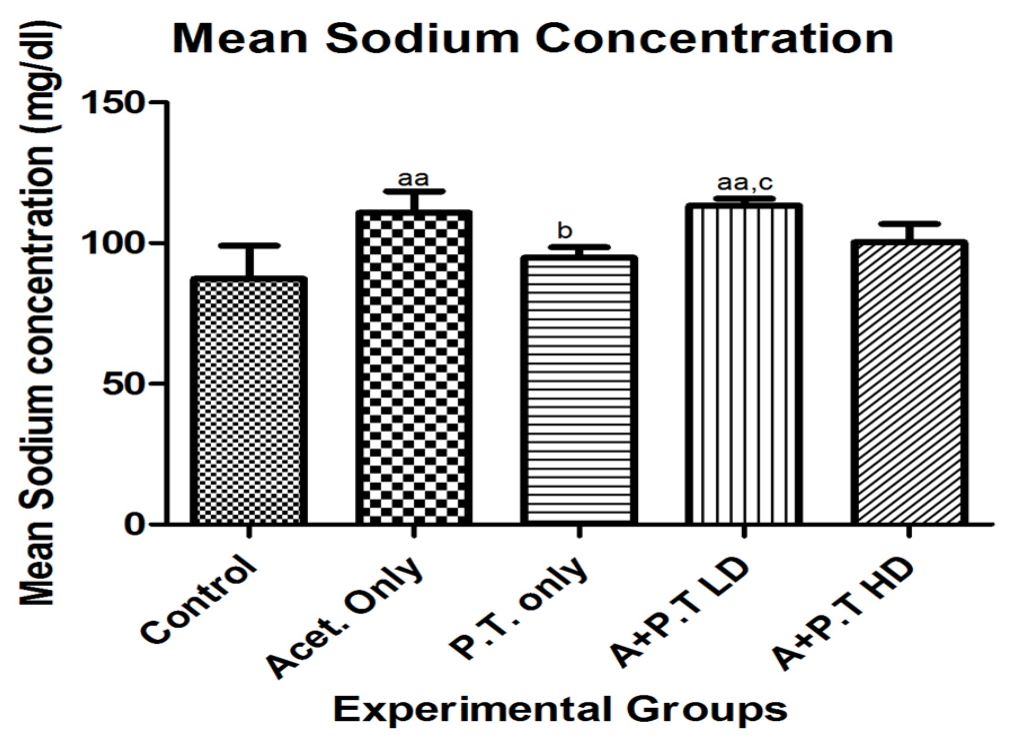

Figure 1 Effect of serum electrolyte of sodium concentration on prenatal exposure to Piliostigma thonningii on renal function indices following acetaminophen induced toxicity of Wistar rats.

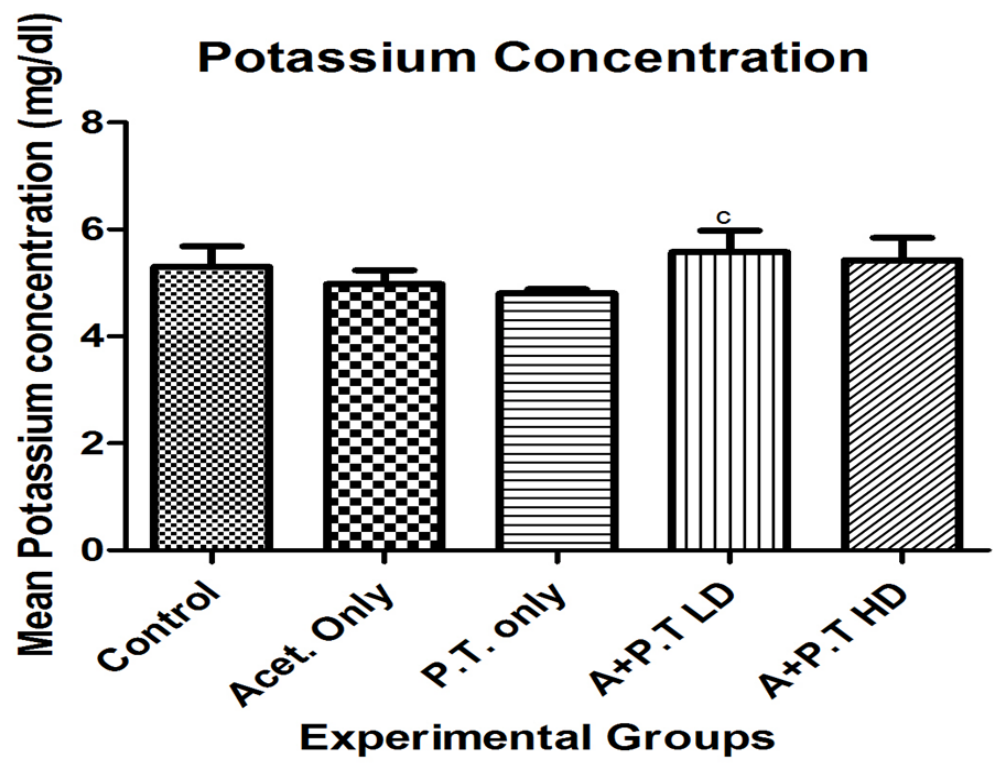

Figure 2 Effect of serum electrolyte of potassium concentration on prenatal exposure to Piliostigma thonningii on renal function indices following acetaminophen induced toxicity of Wistar rat. 


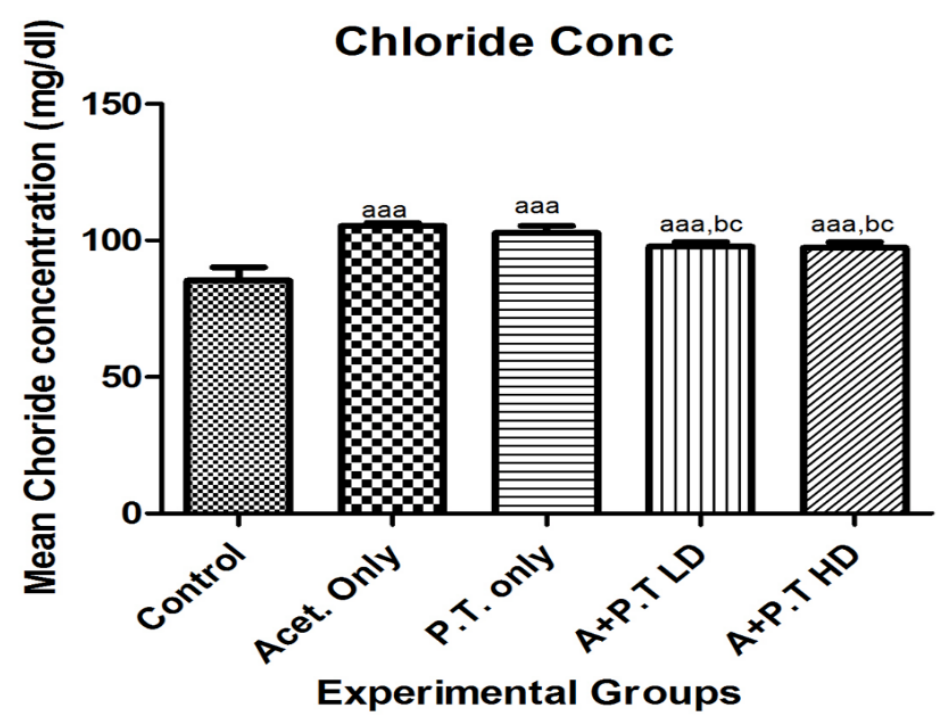

Figure 3 Effect of serum electrolyte of chloride concentration on prenatal exposure to Piliostigma thonningii on renal function indices following acetaminophen induced toxicity of Wistar rats.

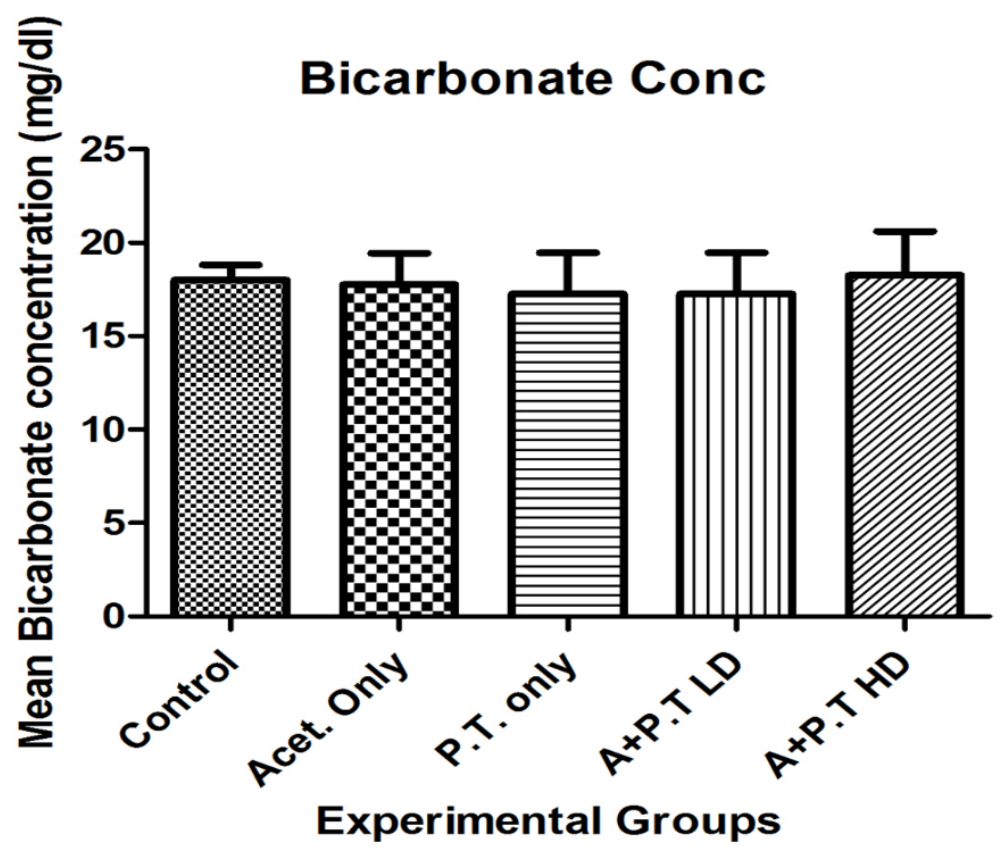

Figure 4 Effect of serum electrolyte of bicarbonate concentration on prenatal exposure to Piliostigma thonningii on renal function indices following acetaminophen induced toxicity of Wistar rats. 


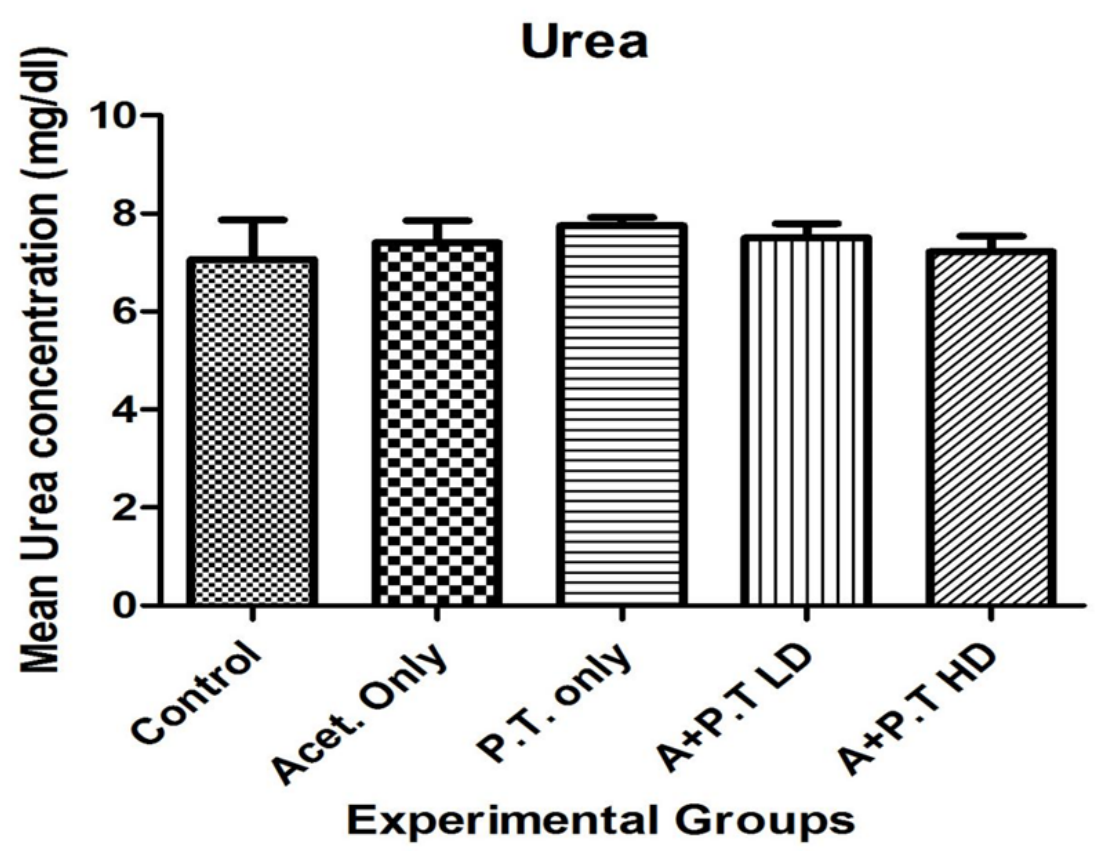

Figure 5 Effect of serum electrolyte of urea concentration on prenatal exposure to Piliostigma thonningii on renal function indices following acetaminophen induced toxicity of Wistar rats.

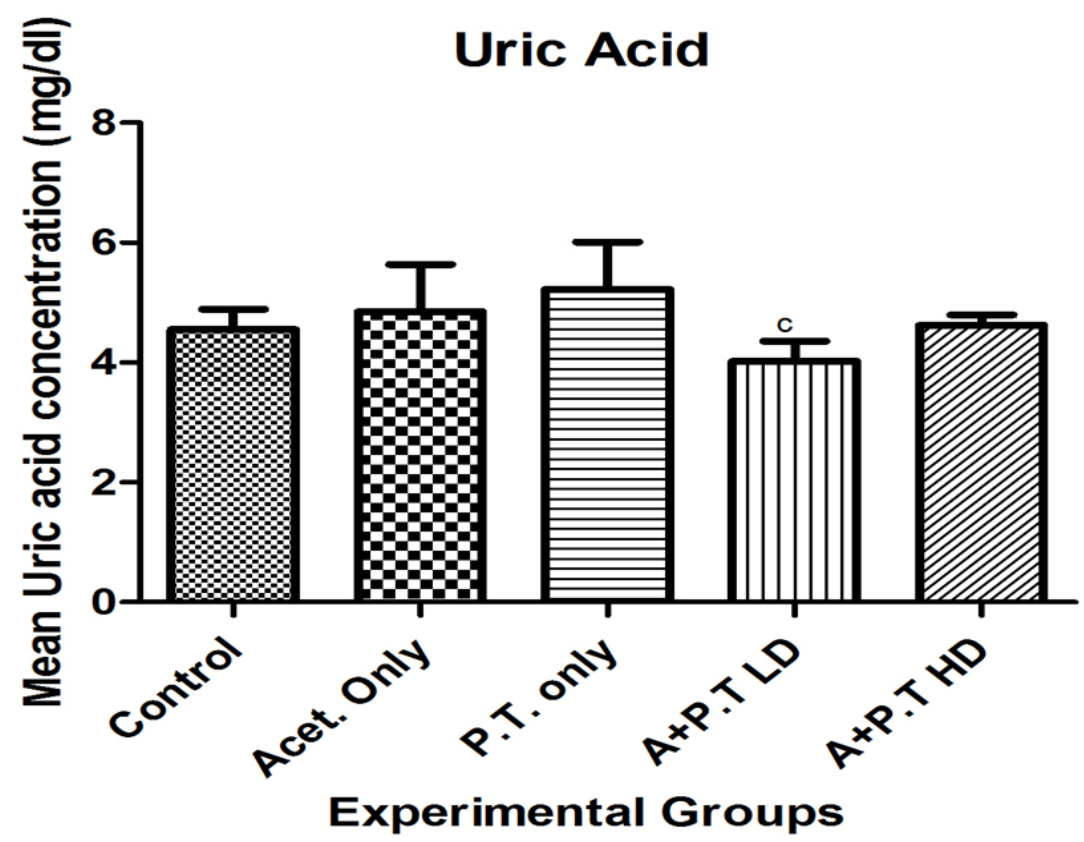

Figure 6 Effect of serum electrolyte onuric acid concentration on prenatal exposure to Piliostigma thonningii on renal function indices following acetaminophen induced toxicity of Wistar rats 


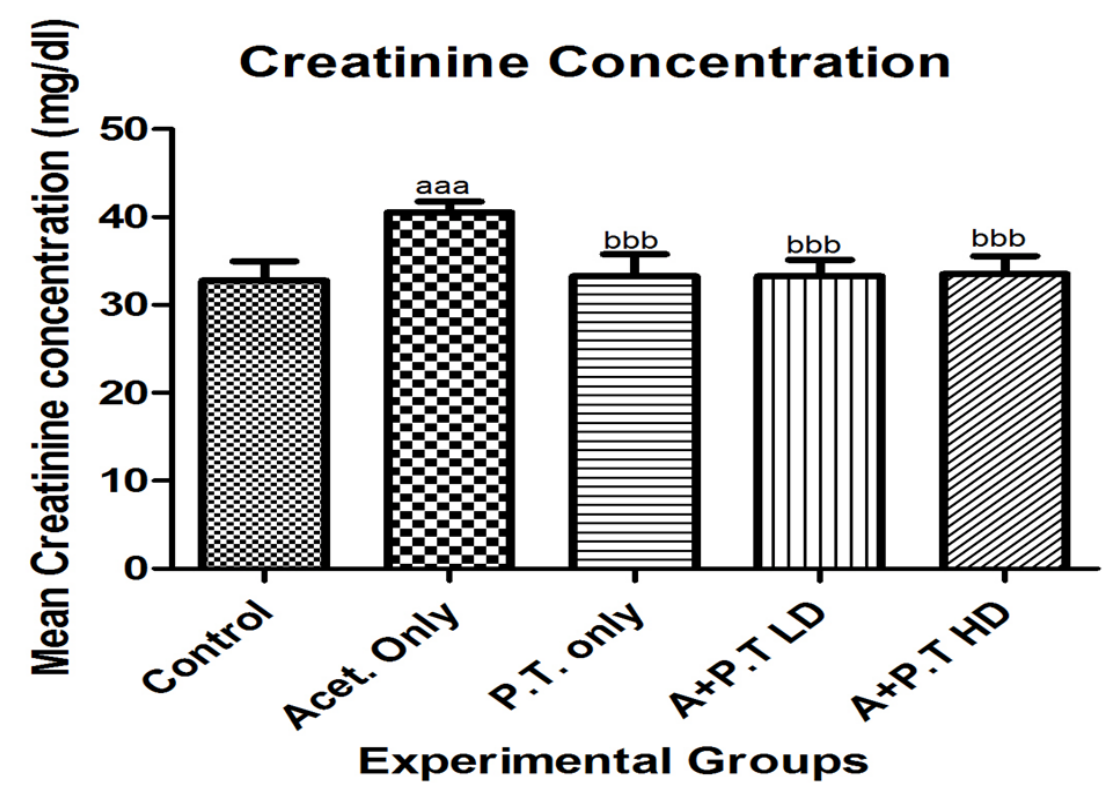

Figure 7 Effect of serum electrolyte of creatinine concentration on prenatal exposure to Piliostigma thonningii on renal function indices following acetaminophen induced toxicity of Wistar rats

\section{AST}

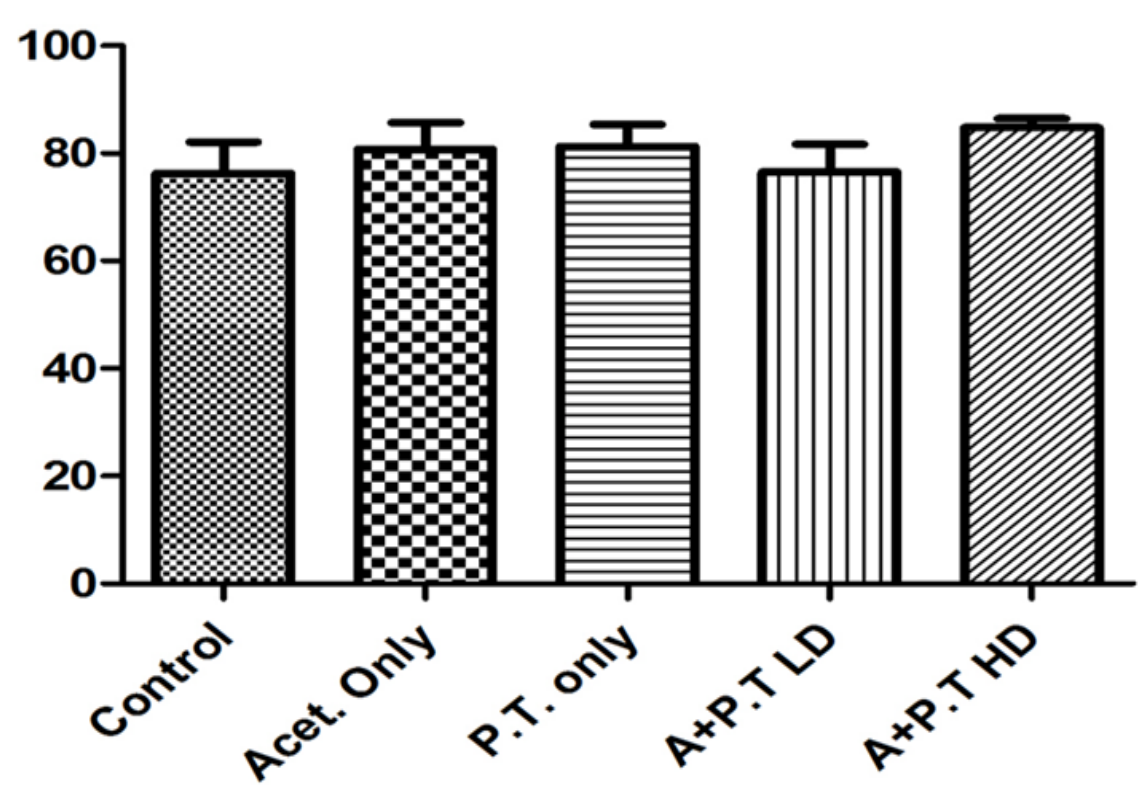

Figure 8 Effect of serum enzyme assay of aspartate amino transferase concentration on the effect of prenatal exposure to Piliostigma thonningii on renal function indices following acetaminophen induced toxicity of Wistar rats 


\section{ALT}

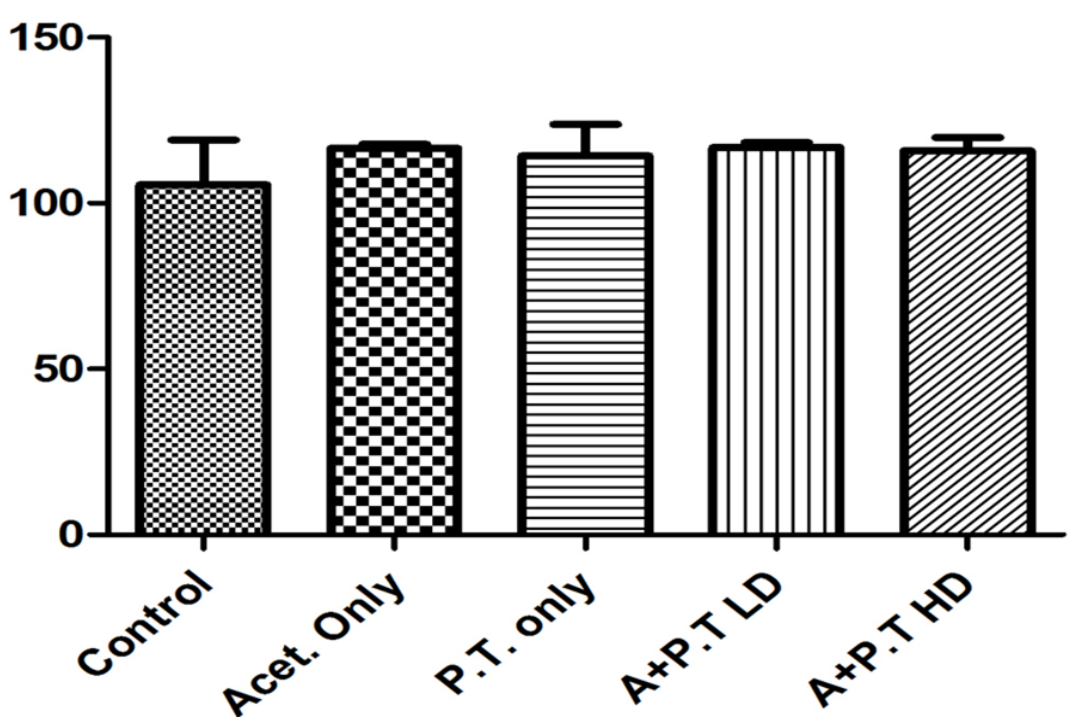

Figure 9 Effect of serum enzyme assay of alanine transaminase concentration on the effect of prenatal exposure to Piliostigma thonningii on renal function indices following acetaminophen induced toxicity of Wistar rats.

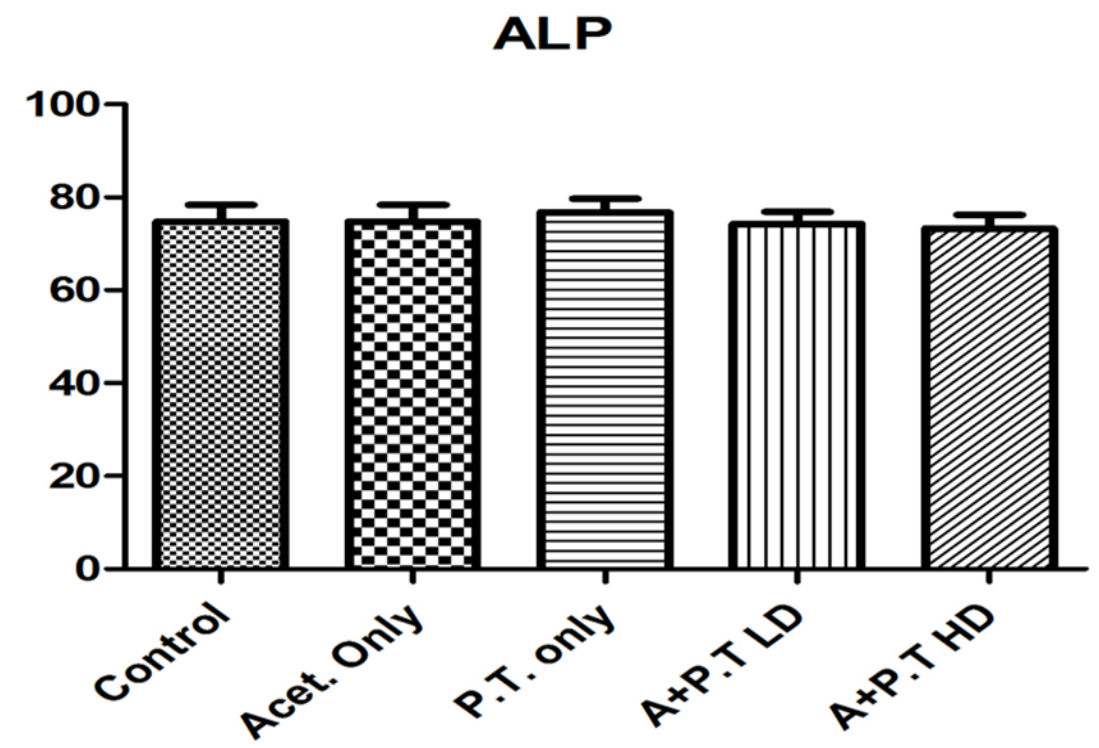

Figure 10 Effect of serum enzyme assay of alkaline phosphatase concentration on the effect of prenatal exposure to Piliostigma thonningii on renal function indices following acetaminophen induced toxicity of Wistar rats.

\section{Discussion}

Acetaminophen (APAP) is one of the most commonly used antipyretic and analgesic drug. When taken at therapeutic doses, it is considered to be a safe drug. Overdose can result in both liver and renal injuries [7]. There is increased concern about exposure to xenobiotic chemicals during gestation through developmental disruption that may result in long-lasting consequences extending into adulthood, resulting in compromised reproductive health. The kidneys are highly susceptible to toxicants because large amounts of toxins carried in the blood, which can concentrate in the kidney tubules flows through it. It can result in systemic toxicity causing decreased ability to excrete body wastes, inability to maintain body fluid and electrolyte balance and decreased synthesis of essential hormones [8]. During pregnancy, women undergo several physiological and biochemical changes such as haematological, hormonal and renal function 
among others. The assessment of serum creatinine, urea, uric acid and electrolyte can be a reliable means of assessing the kidney function of pregnant women worldwide and evaluating the risk to the life of pregnant mother and their foetus due to changes in renal function during pregnancy[9].

The observed increase on prenatal serum sodium ion concentration following the administration of acetaminophen and the resultant increase upon treatment with P.T at graded doses suggests that the extract may induce hypernatremia on prenatal exposure possibly by increasing the serum aldosterone levels.

More so, the non-significant difference in potassium, chloride and bicarbonate ion concentration following prenatal exposure to acetaminophen and ethanol extract of $P$ thonningii might be due to non-competitive action of progesterone that connects to the mineralocorticoid receptors located in the distal portions of the nephron and also suggest that the extract has no assault to the functional integrity of the kidney.

Urea is a major nitrogenous end product of protein and amino acid catabolism, produced by liver and distributed throughout intracellular and extracellular fluid. .In kidneys, urea is filtered out of blood by glomeruli and is partially being reabsorbed with water [10]. The most frequently determined clinical indices for estimating renal function depends upon concentration of urea in the serum. It is useful in differential diagnosis of acute renal failure and pre renal condition where blood urea nitrogen-creatinine ratio is increased [11]. Urea clearance is a poor indicator of glomerular filtration rate as its overproduction rate depends on several non-renal factors, including diet and urea cycle enzymes. Increased blood urea nitrogen (BUN) is seen associated with kidney disease or failure, blockage of the urinary tract by a kidney stone, congestive heart failure, and dehydration and bleeding in the digestive tract. High BUN levels can sometimes occur during late pregnancy or result from eating large amounts of protein-rich foods. If the BUN level is higher than $100 \mathrm{mg} / \mathrm{dL}$ it points to severe kidney damage whereas decreased BUN is observed in fluid excess. Low levels are also seen in trauma; surgery, opioids, malnutrition, and anabolic steroid use [12]. Since the prenatal administration of the extract and acetaminophen possess no significant difference on serum urea concentration, it therefore indicates that the extract did not alter the glomerular filtration rate (GFR) nor posed any injury or assault to the integrity of both the nephron and the kidney of neonates.

More so, Creatinine which is derived from creatine phosphate in muscle tissues is defined as a nitrogenous waste product. Creatinine is not reutilized but is excreted from the body in the urine via the kidney. It is produced and excreted at a constant rate which is proportional to the body muscle mass [12]. Creatinine is measured primarily to assess kidney function and has certain advantages over the measurement of urea. The plasma level of creatinine is independent of protein ingestion, water intake, rate of urine production and exercise elevation of plasma creatinine is usually indicative of under-excretion, suggesting kidney impairment [13]. However, in this study, there was no significant change in the level of creatinine suggesting that it trigers no alteration to the functional capacity of the kidney following prenatal exposure to both acetaminophen and P.thonningii.

\section{Conclusion}

It was speculated that prenatal exposure to acetaminophen produced no assault on the functional integrity of the kidney but with an evidence of hypernatremia which may be due to increase in aldosterone level.

\section{Compliance with ethical standards}

\section{Acknowledgments}

The authors of this research study wish to appreciate the technical assistance of Mr Obogo, Ezikiel of the Department of Medical Biochemistry, Cross River University of Technology, Okuku Campus, Nigeria.

\section{Disclosure of conflict of interest}

The authors have not declared any conflict of interests.

\section{Statement of ethical approval}

Ethical approval for the study was obtained from the Faculty of Basic Medical Science Animal Research Ethical Committee of Cross River University of Technology, Calabar, Nigeria (approval number FBMS/CRUTECH/12/021). 


\section{References}

[1] Abbot FV and Hellemans FG. (2000). Phemecetin acetaminophen and dipyrone: Anagelic and awarding effects Behaviour brain responses, 112, 177-186.

[2] Whelton A. (2003). Renal aspects of treatment with conventional nonsteroidal anti-inflammatory drugs versus cy-Clooxygenase-2-specific inhibitors. Am J Med, 110(Supplement 3A), 33S-42S.

[3] Dasofunjo K, Asuk AA, Ezugwu HC, Nwodo OFC and Olatunji TL. (2013). Aphrodisiac Effect of Ethanol extract of Piliostigma thonnigii Leaf on male Wister Rats. Journal of Applied Pharmaceutical Science, 3(10), 130-135.

[4] Dasofunjo K, Asuk AA, Okwari 00 and Oli Mary. (2016). Haematological and Kidney Function Indices of Piliostigma thonningii Leaf Extract Administration Following Pefloxacin Induced Toxicity in Wistar Rats. British Journal of Medicine \& Medical Research, 16(11), 1-8.

[5] Dasofunjo K, Ipav SS and Ezugwu CH. (2014).Antimicrobial and Bioactive Potential of Piliostigma thonningii leaf. Journal of Pure and Applied Sciences, 5(1), 135-141.

[6] Dasofunjo K, Nwodo OFC, Ezugwu HC, Atunka EA and Onah LN. (2018). Impact of oral administration of Ethanol leaf extract of Piliostigma thonningii on fertility hormones of male Wistar rats. Perspectives in Medical Research, $6(2), 16-20$.

[7] Cholongitas E, Shusang V and Marelli L. (2007). Review article: renal function assessment in cirrhosis - difficulties and alternative measurements. Aliment Pharmacol Ther, 26(7), 969-978.

[8] Krane NK and Hamrahian M. (2007). Pregnancy: Kidney Diseases and Hypertension. American Journal of Kidney Diseases, 49(2), 336-345.

[9] Adebayo JO, Yakubu MT, Egwin EO, Owoyele VB and Enaibe BU. (2003). Effect of Ethanolic extract of Khaya Senegalensis on some biochemical parameters of rat kidney. Journal ethnopharmacol, 88, 69-72.

[10] Miller W, Myers and Ashwood E. (2005). Creatinine measurement: state of the art in accuracy and interlaboratory harmonization. Arch Pathology Laboratory Medicine, 129(3), 297-304.

[11] Banfi Gas and Del F. (2008). Serum creatinine values in elite athletes competing in 8 different sports: comparison with sedentary people. Clinical Chemistry, 52, 330-331.

[12] Dharnidharka VR, Kwon C and Stevens G. (2002). Serum cystatin C is superior to serum creatinine as a marker of kidney function: a meta-analysis. Am J Kidney Dis, 40, 221-226.

[13] Yuegang Z and Chengjun W. (2008). Simultaneous Determination of Creatinine and Uric Acid in Human Urine by High Performance Liquid Chromatography. Annals of Science, 24, 1589-1592.

\section{How to cite this article}

Nkanu EE, Dasofunjo K, Ujong UP and Amaku EE. (2020). Physiological and Biochemical implication of prenatal exposure to acetaminophen and Piliostigma thonningii extract on the renal function indices of female rats. GSC Biological and Pharmaceutical Sciences, 12(1), 15-24. 